\title{
In vitro acetylcholinesterase inhibitory activity and chemical composition of the dichloromethane extracts of the leaves and inflorescences of the tumbleweed, Trachyandra laxa (N.E.Br.) Oberm. var. rigida (Suesseng.) Roessl
}

\author{
Hedwig M. Van Wyk ${ }^{\mathrm{a}}$, Dewald Schoeman ${ }^{\mathrm{b}}$, Ezekeil Kwembeya ${ }^{\mathrm{c}}$, Renate H. Hans ${ }^{\mathrm{a}}$, \\ Edmund J. Pool ${ }^{\mathrm{b}}$, Stefan Louw ${ }^{\mathrm{a}, *}$ \\ ${ }^{a}$ Department of Physics, Chemistry and Material Science, University of Namibia, Namibia \\ ${ }^{\mathrm{b}}$ Department of Medical Bioscience, University of the Western Cape, Republic of South Africa \\ ${ }^{\mathrm{c}}$ Department of Environmental Science, University of Namibia, Namibia
}

\section{A R T I C L E I N F O}

\section{Article History:}

Received 30 July 2021

Revised 24 November 2021

Accepted 13 December 2021

Available online $\mathrm{xxx}$

Edited by Prof. J.J.M. Meyer

KEYWORDS:

Neurotoxicity

Livestock poisoning

Acetylcholinesterase inhibition

$\alpha, \beta$-unsaturated lactone

dihydroactinidiolide

phytol

\begin{abstract}
A B S T R A C T
Trachyandra laxa, which belongs to the family Asphodelaceae, is a poisonous geophyte, often consumed by livestock, particularly when pastures are poor. Ingestion of T. laxa by livestock causes paresis and paralysis of the animals. However, the chemical composition of this plant has never been studied before and its toxic components are still unknown. In this study, an acetylcholinesterase (AChE) inhibition assay of different extracts of the parts of Trachyandra laxa (N.E.Br.) Oberm. var. rigida (Suesseng.) Roessl. revealed that the DCM extracts possess the highest AChE inhibitory activity. In addition, using qualitative phytochemical tests, it was determined that all the plant parts contain polyphenols and tannins, while only the leaves contain flavonoids. Saponins were detected in all plant parts, except in the flowers and anthraquinones were detected in all plant parts expect the roots. Using GC-MS analysis, 13 volatile constituents were identified in the DCM extracts of the leaves and inflorescences, including $\alpha, \beta$-unsaturated lactones, carboxylic acids and esters, a diterpenoid, phytol, and a phytosterol, $\beta$-sitosterol. Of particular interest are the $\alpha$, $\beta$-unsaturated lactones, which were identified as dihydroactinidiolide (DHA) and its hydroxylated analogue, hydroxy-DHA, as well as phytol, a diterpenoid. DHA and phytol have been reported to possess potent AChE inhibition activity. It is therefore plausible that these compounds and potentially also hydroxy-DHA could contribute to the AChE inhibitory activity of the DCM extracts, and thus the neurotoxicity of T. laxa var. rigida.
\end{abstract}

(c) 2022 SAAB. Published by Elsevier B.V. All rights reserved.

\section{Introduction}

Poisonous plants are a major concern for livestock farming in southern Africa (Mannheimer et al., 2012; Schubert, 2002). Usually, plant poisoning in animals occurs accidentally during unfavourable conditions when pastures are poor due to drought, veld fires, and overstocking, when animals are forced to eat poisonous plants which would normally be avoided. Poisonous plants can affect the entire spectrum of organ systems, with some plants having several toxic principles that affect different systems (Schubert, 2002). Two varieties of Trachyandra laxa occur in Namibia namely, Trachyandra laxa (N.E.Br.) Oberm. var. laxa and Trachyandra laxa (N.E.Br.) Oberm. var. rigida (Suesseng.) Roessl. Trachyandra laxa (N.E.Br.) Oberm. var. rigida

\footnotetext{
* Corresponding author at: Department of Physics, Chemistry and Material Science, University of Namibia, Room W287, 340 Mandume Ndemufayo Avenue, Pionierspark, Windhoek, Namibia.

E-mail addresses: slouw@unam.na, stefanlouw@gmail.com (S. Louw).
}

(Suesseng.) Roessl are robust and coarse plants that have trichotomous lower inflorescence branches, clavate peduncles at the apex and swollen (but not tuberous) long and spreading roots. They are perennial geophytes, with tough, fleshy, bilaterally flattened, terete leaves in a basal rosette. The tepals are white with a narrow purplebrownish central stripe. Trachyandra laxa (N.E.Br.) Oberm. var. laxa are slender plants that have alternate inflorescence branches from the base upwards, peduncles not clavate at the apex and tuberous roots (Grant et al., 1985; Kativu, 1996).

Consumption of Trachyandra laxa (N.E.Br.) Oberm. var. laxa causes progressive paresis (partial paralysis) and paralysis in cattle, goats, sheep, horses and pigs and is characterized by the accumulation of a brownish pigment, consistent with lipofuscin, mainly in the larger neurons of the brain and spinal cord (Grant et al., 1985). Poisoned animals develop a number of symptoms consistent with central nervous system toxicity, including tremors or muscle twitching, paresis and paralysis which results in sternal recumbence (Botha and 
Penrith, 2008; Grant et al., 1985; Mannheimer et al., 2012; Schubert, 2002). In another study it was reported that a similar lipofuscin storage disease caused paresis in sheep with the ingestion of another Trachyandra species, T. divaricata (Jacq.) Kunth (Newsholme et al., 1985).

Plant toxicity may be due to the presence of a diversity of primary and secondary metabolites that include alkaloids, triterpenes, steroids, saponins, anthraquinones, glycosides, proteins and amino acids (Kellerman et al., 2005). Numerous phytoconstituents, including alkaloids, coumarins, terpenoids, and polyphenols have been identified as a natural source of acetylcholinesterase (AChE) inhibitors (Dos Santos et al., 2018). When compounds inhibit AChE enzymes and cause a disruption of neurotransmission, they are essentially acting as neurotoxins (Čolović et al., 2013). Therefore, in vitro AChE inhibition assays are commonly used for the determination of the presence of neurotoxins (Hendricks and Pool, 2012; Lionetto et al., 2013). AChE hydrolyses the substrate acetylcholine (ACh) at the membrane of mammalian neurons and, while predominantly associated with the neuromuscular junction and cholinergic synapses in the central nervous system (CNS), it is also found in the blood where it is associated with erythrocytes, lymphocytes, megakaryocytes, and platelets (Husain, 1994; Paulus et al., 1981; Zajicek, 1957).

AChE is produced from a single gene and can be expressed to produce different isoforms in different tissues through alternative splicing at the 3' terminus of the AChE pre-mRNA (Getman et al., 1992). This can produce three isoforms: the primary isoform found at synapses (AChE-S) in the CNS; a stress-induced, soluble isoform (AChE-R), and the isoform found in the membrane of erythrocytes (AChE-E) (Grisaru et al., 1999; Massoulié, 2002; Meshorer and Soreq, 2006). While AChE-S and AChE-R are predominantly found in neurons, they have also been found in peripheral blood cells (Pick et al., 2004). Despite being located in different tissues and expressed as different isoforms, the variants all share a similar catalytic domain but differ at the C-terminus, which is responsible for the molecular form, localisation, and specific features and the variants (Park et al., 2004). Furthermore, AChE-E can take part in certain reactions in the same way as the other AChE isoforms. For instance, the serine in the active site of AChE-E produces a covalent bond with an organophosphate pesticide in the same way as the AChE isoforms found in the nervous system (Dafferner et al., 2017). Consequently, one version of the AChE assay is performed by using AChE extracted from blood (Ellman et al., 1961; Hendricks and Pool, 2012). Although the AChE used in this case is mostly the erythrocyte isoform it will still provide an indication of neurotoxicity (Dafferner et al., 2017; Gupta et al., 2015).

Trachyandra species have been associated with progressive, ascending paresis and paralysis in cattle, sheep, horses, and pigs in Namibia and South Africa (Kellerman et al., 2005). However, the toxic components of these plants are still unknown (Botha and Penrith, 2008; Van Wyk et al., 2002). Moreover, no studies on the chemical composition of $T$. laxa could be found and no studies have been performed to determine the AChE inhibition properties of this plant either. In this study, the AChE inhibition activities of different extracts of the plant parts of T. laxa (N.E.Br.) Oberm. var. rigida (Suesseng.) Roessl. were determined. The chemical composition of the active extracts was subsequently investigated using gas chromatography mass spectrometry (GC-MS). Furthermore, the different classes of phytochemicals present in the plant parts were determined using qualitative phytochemical tests.

\section{Materials and methods}

\subsection{Chemicals and reagents}

Merck high-performance liquid chromatography (HPLC) grade dichloromethane (DCM; Biodynamics, Windhoek, Namibia) was used to prepare extracts and standard solutions. The alkane mixture $\left(C_{10}-C_{40} n\right.$-alkanes, all with an even number of carbons) used for retention index determinations was of analytical grade and purchased from Sigma-Aldrich (Taufkirchen, Germany). All other chemicals and reagents (methanol, hexane etc.) were of analytical reagent grade (AR). Purified water was obtained using a Milli-Q Integral 3 water purification system. Greiner 96-well microtiter plates were used for the AChE assay and HPLC vials used for storage of sample solutions.

\subsection{Plant material}

Plant material was collected near farm Dakota $35\left(23^{\circ} 04^{\prime} 119^{\prime \prime} \mathrm{S} ; 18^{\circ}\right.$ $28^{\prime} 813^{\prime \prime} \mathrm{E}$ ) in the Omaheke region (research/collection permit number: 1869/2014). Samples of the plant were harvested after the rainy season in February 2014, as they were abundantly available at the time. They were randomly selected, and uprooted. The plants were identified at the National Herbarium of Namibia (National Herbarium of Namibia, identification report number: 2014/348) as T. laxa var. ridiga (Suess) Roessler, from the family Asphodelaceae (Group et al., 2016; Klopper et al., 2013). This plant is commonly known as the tumbleweed (Fig. 1A). A voucher specimen of the plant was deposited at the National Herbarium of Namibia (WIND herbarium).

\subsection{Processing of plant material and preparation of extracts}

The collected plants were carefully separated into their different parts, roots, rhizomes, leaves, inflorescences, and flowers (Fig. 1B).
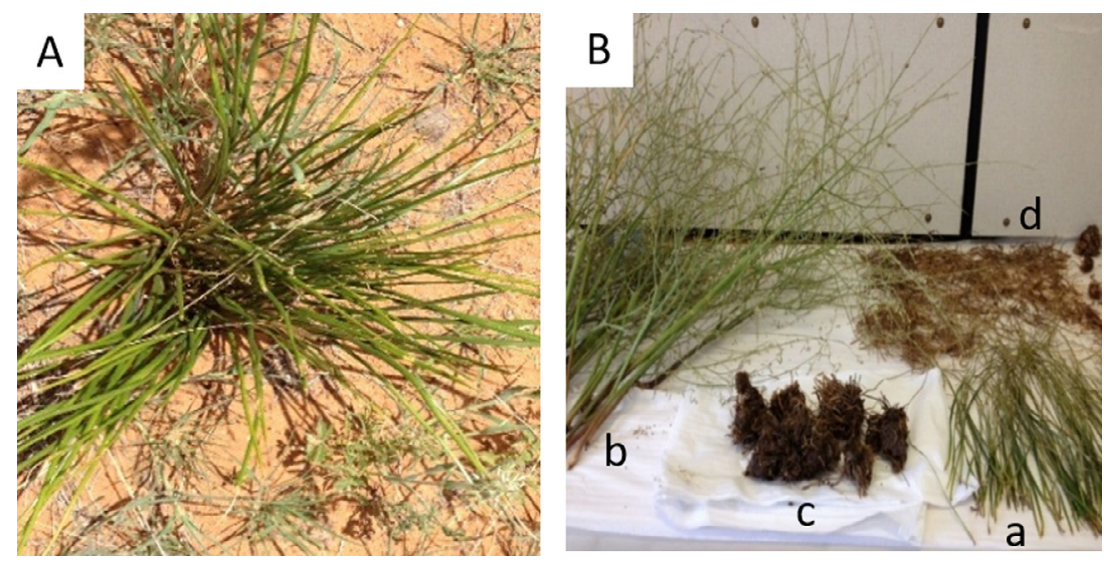

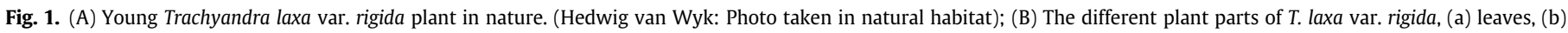
inflorescences, $(\mathrm{c})$ rhizomes and $(\mathrm{d})$ roots. 
Table 1

Yield of crude extracts produced from different plant parts of Trachyandra laxa (N.E.Br.) Oberm. var. rigida by successive maceration with hexane, DCM and $\mathrm{MeOH}$.

\begin{tabular}{llll}
\hline \multirow{2}{*}{ Plant part } & \multicolumn{3}{c}{ Dry extract yield (\%) } \\
\cline { 2 - 4 } & Hexane & DCM & Methanol \\
\hline Leaves & 1.0 & 2.7 & 8.7 \\
Flowers & 1.8 & 2.4 & 9.1 \\
Inflorescences & 0.9 & 0.9 & 7.9 \\
Rhizomes & 0.7 & 4.6 & 8.4 \\
Roots & 0.5 & 2.9 & 9.4 \\
\hline
\end{tabular}

These were cut into smaller pieces and left to dry at room temperature in a well-ventilated room, before being ground into powder. Extracts of the different plant parts were prepared by successive maceration with hexane, dichloromethane (DCM) and methanol $(\mathrm{MeOH})$. Ten grams of the powdered material was extracted with 20 vol of the appropriate solvent for $20 \mathrm{~h}$ at ambient temperature. The filtrates were subsequently concentrated under reduced pressure. The concentrated extracts were then transferred to separate $10 \mathrm{~mL}$ vials where they were dried in a nitrogen atmosphere (Table 1 ). The dried extracts were then stored at $-20^{\circ} \mathrm{C}$.

\subsection{In vitro acetylcholine esterase inhibition assay}

The in vitro AChE inhibition assay was performed on the different extracts by measuring optical densities (ODs) at different time intervals to monitor the change in acetylcholine concentration, using a method adapted from the one used by Hendricks and Pool (Hendricks and Pool, 2012). The assay was performed in triplicate. Phosphate buffer ( $0.1 \mathrm{M}$; $\mathrm{pH} 7.5$ ) was prepared using sodium hydrogen phosphate. Stock solutions of the extracts were prepared in dimethyl sulphoxide (DMSO), at concentrations of ca. $10 \mathrm{mg} / \mathrm{mL}$. A dilution of each extract was prepared in phosphate buffer to obtain final concentrations of $0.1 \mathrm{mg} / \mathrm{mL}$. The positive control consisted of $0.1 \mathrm{mM}$ chlorpyrifos, an organophosphate insecticide that inhibits acetylcholinesterase, prepared in phosphate buffer (Hendricks and Pool, 2012; Rhee et al., 2013). The negative control, 10\% DMSO, was also prepared in phosphate buffer, and serial dilutions of both the positive and negative controls were performed. Blood was collected at the University of the Western Cape from a healthy male volunteer who was not on any medication, using sterile heparin vacutainer tubes (Lasec, South Africa) and stored at room temperature. Blood samples were used for AChE inhibition assays within 30 min of collection. An AChE extract was prepared by mixing the heparinised blood, distilled water and phosphate buffer (in a ratio of 3:20:97). A volume of $25 \mu \mathrm{L}$ of each plant extract solution was added in triplicate to a flat bottom 96 -well microtiter plate followed by $25 \mu \mathrm{L}$ of the AChE extract. A DMSO blank was also prepared which contained $0.1 \%$ DMSO with no sample, and was used to compare AChE enzyme activity. The plate was subsequently left to incubate for two hours. Thereafter, $50 \mu \mathrm{L}$ of substrate solution was added to each well containing sample solution as well as those containing the controls. The substrate solution was prepared by mixing $200 \mu \mathrm{L}$ of $0.01 \mathrm{M}$ 5,5-dithiobis-(2-nitro-benzoic acid), $6 \mu \mathrm{L}$ phosphate buffer and $40 \mu \mathrm{L}$ of $0.075 \mathrm{M}$ freshly prepared acetylthiocholine iodide. Immediately after adding the substrate solution the OD was measured at $405 \mathrm{~nm}$ (BMG Labtech, FLUOstar Omega microtiter plate reader) and then every 15 min for one hour. The AChE enzyme activity was calculated as a percentage of the DMSO blank and the data was expressed as the percentage AChE enzyme activity \pm standard deviation (SD), using the following equation.

Percentage AChE activity $=\left(\frac{\mathrm{OD}_{\text {sample }}}{\mathrm{OD}_{\mathrm{DMSO} \text { blank }}}\right) \times 100$

\subsection{Statistical analysis}

Systat SigmaPlot (v12.2) was used for statistical analysis and figures of statistical relevance were constructed using Graphpad Prism (v5.01). Data was analysed by One Way Analysis of Variance (ANOVA) with the Holm-Sidak test as a multiple comparison test compared to the DMSO blank sample. An overall value of $P<0.05$ was considered statistically significant.

\subsection{Chemical composition}

\subsubsection{Phytochemical screening}

Qualitative chemical tests were carried out on the powdered leaves, inflorescences, rhizomes, roots and flowers of $T$. laxa to determine the presence or absence of selected classes of compounds. Tests were performed in duplicate, based on the methods described by Harborne (Harborne, 1998). The phytochemical screens were also carried out with negative controls in order to compare colour changes. Weak coloration was assigned $a+$ while strong coloration was indicated by +++.

\subsubsection{GC-MS analysis}

GC-MS analysis were performed on a Thermo Scientific Focus GC coupled to an ITQ 700 MS. The flow rate of the carrier gas, helium, was kept constant at $1.0 \mathrm{~mL} / \mathrm{min}$ and a split ratio of 10 was used. A SGE BP5MS capillary GC column ( $30 \mathrm{~m} \times 0.25 \mathrm{~mm}$ i.d), with a $5 \%$ phenyl, 95\% polysilphenylene-siloxane stationary phase $(0.25 \mu \mathrm{m}$ film thickness) was used for the separations. The GC injector temperature was maintained at $220{ }^{\circ} \mathrm{C}$. Ion source and interface temperatures of 200 and $250{ }^{\circ} \mathrm{C}$, respectively, were used for the analysis. The oven was programmed at a rate of $2{ }^{\circ} \mathrm{C} / \mathrm{min}$ from 40 to $300{ }^{\circ} \mathrm{C}$. Electron ionization-Mass Spectrometry (EI-MS) data was acquired at $70 \mathrm{eV}$ and a mass range of $m / z 25$ to 600 was scanned. Data acquisition and processing was performed using Xcalibur Software, version 2.1. A mixture of $n$-alkanes, $C_{7}$ and $C_{10}-C_{40}$ (all even numbers of carbons), was analysed under the same conditions for experimental retention index (RI) determination. Samples were prepared for GC-MS analysis by dissolving each extract in DCM at concentrations of ca. $10 \mathrm{mg} / \mathrm{mL}$. A volume of $1 \mu \mathrm{L}$ of each solution was analysed. To estimate the relative quantities of the compounds that are present in the extracts, a semi-quantitative internal normalisation approach was used, where the relative amounts of the compounds were calculated as percentages of the detected peaks in the total ion chromatogram (TIC) of the GC-MS analysis, by calculating the percentage of each compound's peak area of the total peak area (of all detected peaks) and assuming all response factors to be unity.

\section{Results and discussion}

\subsection{In vitro acetylcholine esterase inhibition activity determination}

The AChE inhibition assay of the different extracts of the leaves, roots, inflorescences, rhizomes and flowers of $T$. laxa revealed high enzyme activities in the DMSO blank as well as most of the extracts, indicating that the DMSO blank and most of the extracts do not inhibit AChE activity (Fig. 2A-C). However, compared to the DMSO blank, a significant decrease in the AChE enzyme activity was observed in the DCM extracts of the leaves $(P<0.001)$, inflorescences $(P<0.001)$, and rhizomes $(P<0.001)$, and hexane extracts of the roots $(P=0.019)$ and rhizomes $(P=0.016)$, suggesting that these extracts inhibited AChE activity the most (Fig. 2A and B). No statistically significant decrease in AChE activity was observed in the methanolic extracts, nor in any of the extracts of the flowers (Fig. 2A-C). The positive control, chlorpyrifos, was able to inhibit between 3 and $80 \%$ of AChE activity within the range of $1.5-100 \mu \mathrm{M}$, with a good 


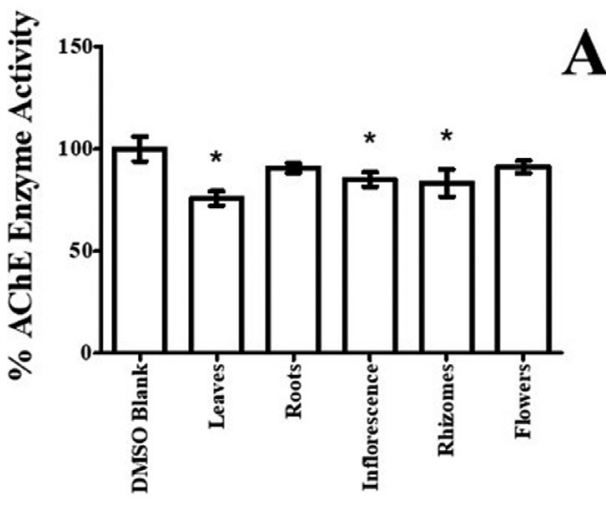

Parts of T. laxa

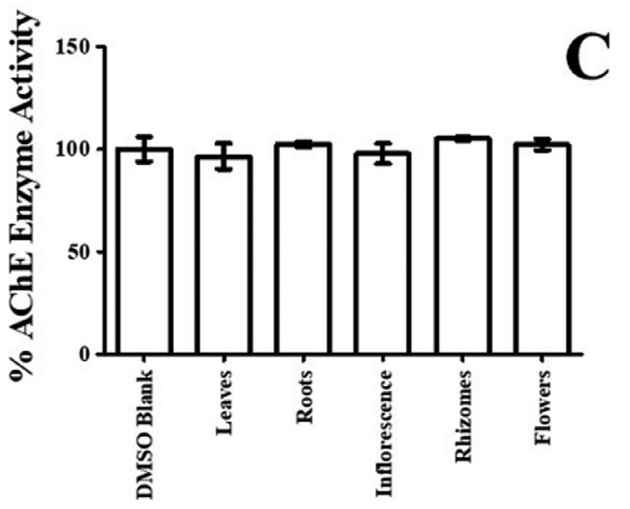

Parts of T. Iaxa

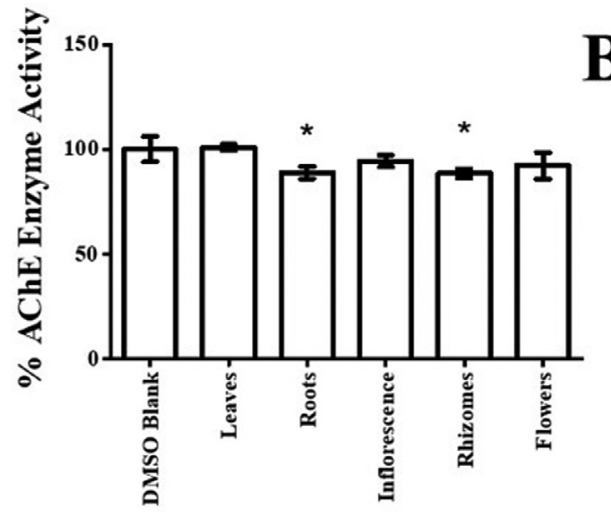

Parts of T. laxa

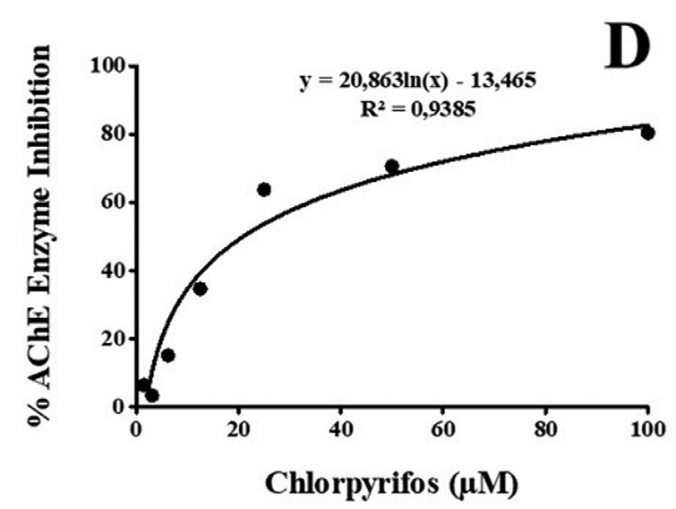

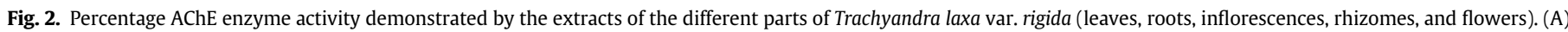

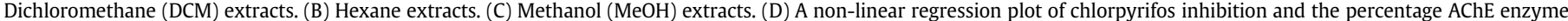

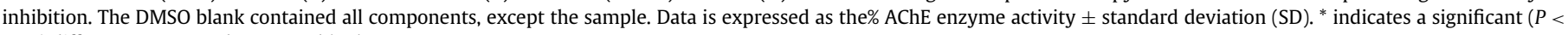
0.05 ) difference compared to DMSO blank.

correlation $\left(R^{2}=0.9385\right)$ between the concentration of chlorpyrifos and the percentage of AChE inhibition (Fig. 2D).

In a recent review of acetylcholinesterase inhibitors from southern African plants it was reported that for most plants the root and bulb extracts exhibit the highest AChE inhibitory activity (Masondo et al., 2019). Interestingly, in our study, the DCM extract of the leaves displayed the best AChE inhibitory activity, with an AChE inhibition of ca. $25 \%$ at an extract concentration of $0.05 \mathrm{mg} / \mathrm{mL}$. One example of a plant of the Asphodelaceae family that exhibit AChE inhibitory activity, in addition to its antiinflammatory and antioxidant properties, is Aloe ferox Mill. It was reported that the effective inhibition concentration $\left(\mathrm{EC}_{50}\right)$ of the $50 \%$ methanol, petroleum ether and DCM extracts of $A$. ferox leaves against AChE was 84.0, 37.7 and $62.6 \mu \mathrm{g} / \mathrm{mL}$, respectively (Fawole et al., 2010).

\subsection{Chemical composition}

\subsubsection{Phytochemical screening}

Phytochemical screening was performed to detect the classes of compounds that are present in the different parts of the plant (Table 2). All the plant parts tested positive for polyphenols and tannins. Saponins were detected in all the plant parts except the flowers, while anthraquinones were found to be present in all the plant parts except for the roots. The leaves were the only plant part where flavonoids could be detected. The presence of anthraquinones have been reported to be a common characteristic of the Asphodelaceae family (previously known as the Xanthorrhoaceae family) (Chien et al., 2015). In addition, Wink and Van Wyk (Wink and van Wyk, 2008) reported that most saponins and anthraquinones are toxic as well as certain tannins. Significant acetylcholine esterase (AChE) inhibition was demonstrated for flavonols isolated from the methanol leaf extract of Maytenus robusta (Celastraceae) (Sousa et al., 2017) and flavonoids from the ethyl acetate extracts of whole plants of Agrimonia pilosa ledeb (Rosaceae) (Jung and Park, 2007). Alkaloids, anthranoids, cardenolides, terpenes and leucoanthocyanins were not detected in any plant parts.

Table 2

Classes of phytochemicals present in the different parts of Trachyandra laxa (N.E.Br.) Oberm. var. rigida.

\begin{tabular}{llllll}
\hline \multirow{2}{*}{ Compounds classes } & \multicolumn{5}{c}{ Plant parts } \\
\cline { 2 - 6 } & Leaves & Inflorescences & Rhizomes & Roots & Flowers \\
\hline Alkaloids & - & - & - & - & - \\
Saponins & $\mathbf{+ + +}$ & $\mathbf{+ + +}$ & $\mathbf{+ +}$ & $\mathbf{+ +}$ & - \\
Anthraquinones & + & ++ & ++ & - & + \\
Anthranoids & - & - & - & - & - \\
Cardenolides & - & - & - & - & - \\
Terpenes & - & - & - & - & - \\
Polyphenols & + & + & ++ & ++ & +++ \\
Flavonoids & + & - & - & - & - \\
Leucoanthocyanins & - & - & - & - & - \\
Tannins & $\mathbf{+ +}$ & $\mathbf{+}$ & $\mathbf{+ +}$ & $\mathbf{+ +}$ & $\mathbf{+ +}$ \\
\hline
\end{tabular}

- not detected.

+ present in small quantities.

++ present in medium quantities.

+++ present in large quantities. 
Table 3

Compounds identified in the DCM extracts of Trachyandra laxa (N.E.Br.) Oberm. var. rigida leaves and inflorescences.

\begin{tabular}{|c|c|c|c|c|c|c|c|c|}
\hline \multirow{2}{*}{$\begin{array}{l}\text { Compound } \\
\text { number }^{\mathrm{a}}\end{array}$} & \multirow[t]{2}{*}{$t_{R}(\min )$} & \multirow[t]{2}{*}{$\mathrm{RI}(\exp )^{\mathrm{b}}$} & \multirow[t]{2}{*}{$\mathrm{RI}(\mathrm{lit})^{\mathrm{c}}$} & \multirow[t]{2}{*}{ Compound } & \multirow{2}{*}{$\begin{array}{l}\text { Identification } \\
\text { methods }^{\mathrm{d}}\end{array}$} & \multirow{2}{*}{$\begin{array}{l}\text { Molecular } \\
\text { formula }\end{array}$} & \multicolumn{2}{|c|}{ Relative quantity $(\%)$} \\
\hline & & & & & & & Leaves & Inflorescences \\
\hline 1 & 16.11 & 1019 & - & Branched $\mathrm{C}_{11}$ alkane & A & $\mathrm{C}_{11} \mathrm{H}_{24}$ & 2.0 & 1.3 \\
\hline 2 & 21.23 & 1106 & - & Unknown alcohol or alkene & A & - & 5.5 & 7.3 \\
\hline 3 & 48.30 & 1516 & $1525^{\mathrm{f}}$ & Dihydroactinidiolide & A, B & $\mathrm{C}_{11} \mathrm{H}_{16} \mathrm{O}_{2}$ & 1.9 & 1.1 \\
\hline 4 & 61.61 & 1751 & $1758^{g}$ & Hydroxy dihydroactinidiolide & $A, C$ & $\mathrm{C}_{11} \mathrm{H}_{16} \mathrm{O}_{3}$ & 4.3 & 1.0 \\
\hline 5 & 66.31 & 1841 & - & Unknown alcohol or alkene & A & - & 1.8 & 0.6 \\
\hline 6 & 70.47 & 1927 & 1921 & Methyl palmitate & A, B & $\mathrm{C}_{17} \mathrm{H}_{34} \mathrm{O}_{2}$ & 6.8 & 0.1 \\
\hline 7 & 72.82 & 1974 & $1973^{\mathrm{h}}$ & Palmitic acid & A, B & $\mathrm{C}_{16} \mathrm{H}_{32} \mathrm{O}_{2}$ & 32.3 & 17.5 \\
\hline 8 & 78.07 & 2090 & 2085 & Methyl linoleate & A, B & $\mathrm{C}_{19} \mathrm{H}_{34} \mathrm{O}_{2}$ & 2.4 & 0.1 \\
\hline 9 & 78.30 & 2095 & $2098^{\mathrm{i}}$ & Methyl linolenate & A, B & $\mathrm{C}_{19} \mathrm{H}_{32} \mathrm{O}_{2}$ & 4.3 & 0.1 \\
\hline 10 & 79.03 & 2111 & $2111^{\mathrm{h}}$ & Phytol & A, B & $\mathrm{C}_{20} \mathrm{H}_{40} \mathrm{O}$ & 2.3 & 0.3 \\
\hline 11 & 80.42 & 2142 & $2143^{j}$ & Linolenic acid & A, B & $\mathrm{C}_{18} \mathrm{H}_{30} \mathrm{O}_{2}$ & 8.4 & 2.4 \\
\hline 12 & 115.70 & 3102 & 3100 & Hentriacontane & A, B & $\mathrm{C}_{31} \mathrm{H}_{64}$ & 1.6 & 27.3 \\
\hline 13 & 121.32 & 3289 & - & $\beta$-sitosterol & A, C & $\mathrm{C}_{29} \mathrm{H}_{50} \mathrm{O}$ & 4.9 & 2.7 \\
\hline
\end{tabular}

a Compounds are numbered in order of elution from the GC column.

b RI values determined experimentally on an HP-5 equivalent column.

c Kovátz RI values reported for authentic reference standards on an HP-5 equivalent column by Adams (Adams, 2007), except where other publications are cited.

d A: Comparison of mass spectrum with NIST MS database and published data, B: RI matches published value (within 10 RI units), C: mass spectrum interpretation.

e Estimated relative amounts of the compounds were calculated as percentages of the detected peaks in the TIC of the GC-MS analysis.

f RI value determined on an HP-5 equivalent column (identified by Pino et al. (Pino et al., 2005) based on comparison with literature MS and RI data only).

g Estimated value based on RI group contribution calculations (Stein et al., 2007).

h RI value reported for authentic reference standard on an HP-5 equivalent column (Maggi et al., 2009).

i RI value reported for authentic reference standard on an HP-5 equivalent column (Edris et al., 2008).

j RI value reported for authentic reference standard on an HP-5 equivalent column (Radulovic et al., 2010).

\subsubsection{Identification of the major volatile constituents in the DCM} extracts of $\mathrm{T}$. laxa plant material by $\mathrm{g} C-\mathrm{MS}$

Based on the results of the acetylcholine inhibition assays, the DCM extracts of the leaves, inflorescences and rhizomes were considered for further investigation. However, since it is only the aerial parts of the plants that are consumed by livestock, the chemical composition of only the DCM extracts of the leaves and inflorescences were determined using GC-MS (Fig. S1). Thirteen compounds, were identified by comparing their mass spectra and RIs to those reported in the literature and those in the National Institute of Standards and Technology (NIST) 11 MS and RI databases (Table 3). In cases where the experimentally determined RIs of the compounds did not differ by more than 10 index units from those reported in the literature, the identity of such compounds were considered to be positively confirmed (provided that the authors reporting the values determined the RIs experimentally using authentic reference standards) (Bicchi et al., 2018). It was found that the extracts comprised a diverse mixture of compounds including $\alpha, \beta$-unsaturated lactones, carboxylic acids and esters, a diterpenoid, phytol, and a phytosterol, $\beta$-sitosterol. Palmitic acid (7) and hentriacontane (12) are the major compounds in the DCM extracts of the leaves and inflorescence, respectively.

Compound $\mathbf{3}$ was tentatively identified as dihydroactinidiolide (DHA) (Fig. 3). This $\alpha, \beta$-unsaturated lactone is commonly found in nature as a degradation product of carotenoids. When $\beta$-carotene is cleaved it gives rise to various compounds like $\beta$-ionone, 5,6-epoxy$\beta$-ionone and DHA (Bosser et al., 1995). In a study conducted by Das et al. (Das et al., 2018) the anti-Alzheimer's disease potential of DHA was investigated and it was found that it is a potent AChE inhibitor with a $\mathrm{IC}_{50}$ value of $34.03 \mathrm{nM}$. In a study of the leaves of Vallisneria. spiralis (family Hydrocharitaceae), DHA was also found to be an active allelochemical which could strongly inhibit the growth of algae and other aquatic macrophytes (Xian et al., 2006).

The mass spectrum of compound $\mathbf{4}$ (Fig. S3) has a similar fragmentation pattern to that of compound 3 (Fig. S2), but with prominent ions at e.g. $m / z 178$ and $m / z 135$, instead of $m / z 180$ and $m / z 137$, respectively. If it is assumed that the ion observed at $m / z 196$, is the molecular ion, then the ion at $m / z 178$ is the $\left[\mathrm{M}-\mathrm{H}_{2} \mathrm{O}\right]^{+} \cdot$ ion and hence it may be inferred that compound $\mathbf{4}$ is a hydroxylated analogue of DHA (3). The ion observed at $m / z 163$ will then correspond to a [M $\left.\mathrm{CH}_{3}-\mathrm{H}_{2} \mathrm{O}\right]^{+}$ion, while the base peak, observed at $m / z 135$, will then be formed by the loss of CO from the ion observed at $\mathrm{m} / \mathrm{z} 163$ (Chen et al., 1970). The RI of compound 4 was experimentally determined to be 1751 . Using the group contribution method for the

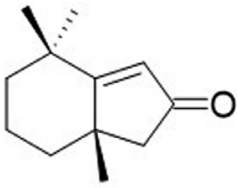

3<smiles>C[C@@]1(CO)CCC[C@]2(C)CC(=O)C=C12</smiles>

$4 *$<smiles>CCCCCCCCCCCCCCCC(=O)O</smiles><smiles>C/C(=C\CO)CCC[C@H](C)CCC[C@H](C)CCCC(C)C</smiles>

10

Fig. 3. Structures of the compounds identified in the DCM extracts of Trachyandra laxa var. rigida leaves and inflorescences that could contribute to the neurotoxicity of the plant (*one of the possible structures). 
estimation of Kováts RIs (Stein et al., 2007), the experimental RI value of compound 4 can be explained by using the experimentally determined RI value of DHA (3) and subtracting the group increment of a methyl group (112 index units (iu)), and adding the group increments of a methylene group (99 iu) and a primary hydroxyl group (225 iu). This brings the estimated RI value to 1758, which is within 10 units of the experimentally determined value of compound 4 . This provides corroborating evidence that compound $\mathbf{4}$ is a hydroxylated analogue of DHA (3), and it also suggests that the hydroxyl group is located at a terminal position (Fig. 3). The compounds loliolide, DHA and actinidiolide are structurally similar C11-terpene lactones which arise from biological or oxidative degradation of carotenoids. Loliolide, a hydroxylated analogue of DHA with the hydroxyl group situated on the molecule's six membered ring, is found in a number of plants, including tobacco and tea, while DHA and actinidiolide have been identified as flavour compounds in tea and tobacco (Eidman and MacDougall, 2006). Interestingly, it has been reported that certain $\alpha, \beta$-unsaturated sesquiterpene lactones are toxic to animals (Van Wyk et al., 2002). Although compounds $\mathbf{3}$ and $\mathbf{4}$ are not sesquiterpenoids, it is conceivable that they could contribute to the toxicity of T. laxa. due to the $\alpha, \beta$-unsaturated lactone moeity in their structures.

Two other compounds that may also contribute to the neurotoxicity of the T. laxa extracts is phytol (10) and palmitic acid (7). Phytol (10) (Fig. 3) is reported to have a wide range of biological activities including anxiolytic, metabolism-modulating, cytotoxic, antioxidant, autophagy- and apoptosis-inducing, antinociceptive, anti-inflammatory, immune-modulating, and antimicrobial effects (Islam et al., 2018). In two recent studies, phytol was found to exhibit significant AChE and butyrylcholinesterase inhibitory potential (Sathya et al., 2020, 2018). The saturated fatty acid, palmitic acid (7) (Fig. 3), was implicated in neuronal loss through lipid-induced enteric nervous system neuropathy (Voss et al., 2013). No reports could be found of any potential neurotoxic effects of the remaining compounds identified in the T. laxa extracts (according to PubChem data). It is noteworthy that since the hexane extracts of the rhizomes and roots also exhibit inhibitory activity, the plant contains additional inhibitors with lower polarities than those identified here.

\section{Conclusion}

In this study, the AChE inhibition properties and chemical composition of T. laxa was investigated for the first time. Interestingly, only the DCM and hexane extracts of certain parts of the plant displayed significant AChE inhibitory activity. Qualitative phytochemical screen tests provided an overview of the classes of phytochemicals present in the plant. Subsequently, the detailed determination of the chemical composition of the DCM extracts of the aerial parts (leaves and inflorescences) of the plant by GC-MS led to the discovery that known AChE inhibitors, DHA (3) and phytol (10) are present in the extracts. These compounds are therefore expected to contribute to the AChE inhibitory activity of the DCM extracts and possibly the neurotoxicity of $T$. laxa. In subsequent studies, hydroxy-DHA (4) should be isolated for full characterisation and AChE inhibitory activity testing. In addition, the DCM and hexane extracts of the rhizomes, as well as the hexane extracts of the roots, which also exhibited AChE inhibition activity, should be chemically characterised. In particular, the hexane extracts are expected to contain non-polar inhibitors not found in the DCM extracts investigated in this study.

\section{ORCID}

Hedwig van Wyk ID: http://orcid.org/0000-0002-8343-9881 Dewald Schoeman ID: https://orcid.org/0000-0003-0086-5154 Ezekeil Kwembeya ID: https://orcid.org/0000-0002-9584-2897 Renate Hans ID: https://orcid.org/0000-0002-2924-0601 Stefan Louw ID: http://orcid.org/0000-0002-3122-8812

\section{Declaration of competing interest}

The authors declare that they have no known competing financial interests or personal relationships that could have appeared to influence the work reported in this paper.

\section{Acknowledgements}

This work forms part of a Master study undertaken at the University of Namibia (UNAM). The study could be performed, thanks to the Namibia/South Africa Collaborative Research Programme grant from the NCRST/NRF, as well as the University of Namibia Research and Publications Committee (URPC) Research Grants [grant number URPC/2013/102]. We would also like to thank the Ministry of Agriculture, Water and Forestry of Namibia, the National Herbarium of Namibia as well as the Department of Chemistry and Biochemistry of UNAM for their support. The views and opinions expressed herein are our own and do not necessarily represent those of UNAM.

\section{Supplementary materials}

Supplementary material associated with this article can be found in the online version at doi:10.1016/j.sajb.2021.12.013.

\section{References}

Adams, R.P., 2007. Identification of Essential Oil Components by Gas Chromatography Mass Spectrometry. Allured Publishing Corporation, Carol Stream, IL, USA.

Bicchi, C., Chaintreau, A., Joulain, D., 2018. Identification of flavour and fragrance constituents. Flavour. Fragr. J. 33, 201-202.

Bosser, A., Paplorey, E., Belin, J.-.M, 1995. A Simple Way to ( \pm )-Dihydroactinidiolide from $\beta$-Ionone Related to the Enzymic Co-oxidation of $\beta$-Carotene in Aqueous Solution. Biotechnol. Prog. 11, 689-692.

Botha, C.J., Penrith, M.L., 2008. Poisonous plants of veterinary and human importance in southern Africa. J. Ethnopharmacol. 119, 549-558.

Chen, P.H., Kuhn, W.F., Will, F., Ikeda, R.M., 1970. High resolution mass spectrometric studies of some bicyclic $\gamma$-lactones. Org. Mass Spectrom. 3, 199-209.

Chien, S.-.C., Wu, Y.-.C., Chen, Z.-.W., Yang, .W.-.C., 2015. Naturally Occurring Anthraquinones: chemistry and Therapeutic Potential in Autoimmune Diabetes. Evidence-Based Complement. Altern. Med. 2015, 357357.

Colović, M.B., Krstić, D.Z., Lazarević-Pašti, T.D., Bondžić, A.M., Vasić, V.M., 2013. Acetylcholinesterase inhibitors: pharmacology and toxicology. Curr. Neuropharmacol. $11,315-335$.

Dafferner, A.J., Schopfer, L.M., Xiao, G., Cashman, J.R., Yerramalla, U., Johnson, R.C. Blake, T.A., Lockridge, O., 2017. Immunopurification of acetylcholinesterase from red blood cells for detection of nerve agent exposure. Chem. Res. Toxicol. 30, 1897-1910.

Das, M., Prakash, S., Nayak, C., Thangavel, N., Singh, S.K., Manisankar, P., Devi, K.P., 2018. Dihydroactinidiolide, a natural product against $A \beta 25-35$ induced toxicity in Neuro2a cells: synthesis, in silico and in vitro studies. Bioorg. Chem. 81, 340-349.

Dos Santos, T.C., Gomes, T.M., Pinto, B.A.S., Camara, A.L., De Andrade Paes, A.M., 2018 Naturally occurring acetylcholinesterase inhibitors and their potential use for Alzheimer's disease therapy. Front. Pharmacol. 9, 1-14.

Edris, A.E., Chizzola, R., Franz, C., 2008. Isolation and characterization of the volatile aroma compounds from the concrete headspace and the absolute of Jasminum sambac (L.) Ait. (Oleaceae) flowers grown in Egypt. Eur. Food Res. Technol. 226 621-626.

Eidman, K.F., MacDougall, B.S., 2006. Synthesis of Loliolide, Actinidiolide, Dihydroactinidiolide, and Aeginetolide via Cerium Enolate Chemistry. J. Org. Chem. 71, 95139516.

Ellman, G.L., Courtney, K.D., Andres, V.J., Feather-Stone, R.M., 1961. A new and rapid colorimetric determination of acetylcholinesterase activity. Biochem. Pharmacol. 7, 88-95.

Fawole, O.a., Amoo, S.O., Ndhlala, a.R., Light, M.E., Finnie, J.F., Van Staden, J., 2010. Antiinflammatory, anticholinesterase, antioxidant and phytochemical properties of medicinal plants used for pain-related ailments in South Africa. J. Ethnopharmacol. 127, 235-241.

Getman, D.K., Eubanks, J.H., Camp, S., Evans, G.A., Taylor, P., 1992. The human gene encoding acetylcholinesterase is located on the long arm of chromosome 7. Am. J. Hum. Genet. 51, 170-177.

Grant, R.C., Basson, P.A., Kidd, A.B., 1985. Paralysis and lipofuscin-like pigmentation of farm stock caused by the plant, Trachyandra laxa var. laxa. Onderstepoort J. Vet. Res. 52, 255-259.

Grisaru, D., Sternfeld, M., Eldor, A., Glick, D., Soreq, H., 1999. Structural roles of acetylcholinesterase variants in biology and pathology. Eur. J. Biochem. 264, 672-686.

Group, T.A.P., Chase, M.W., Christenhusz, M.J.M., Fay, M.F., Byng, J.W., Judd, W.S. Soltis, D.E., Mabberley, D.J., Sennikov, A.N., Soltis, P.S., Stevens, P.F., 2016. An 
update of the Angiosperm Phylogeny Group classification for the orders and families of flowering plants: APG IV. Bot. J. Linn. Soc. 181, 1-20.

Gupta, V.K., Pal, R., Siddiqi, N.J., Sharma, B., 2015. Acetylcholinesterase from human erythrocytes as a surrogate biomarker of lead induced neurotoxicity. Enzyme Res 2015.

Harborne, J.B., 1998. Phytochemical Methods A Guide to Modern Tecniques of Plant Analysis, 3rd Edition Chapman Hall, p. 58.

Hendricks, R., Pool, E.J., 2012. Rapid in vitro tests to determine the toxicity of raw wastewater and treated sewage effuents. Water SA 38, 807-812.

Husain, K., 1994. Phenyl valerate and choline ester hydrolases in the platelets of human, hen, rat and mouse. Hum. Exp. Toxicol. 13, 157-159.

Islam, M.T., Ali, E.S., Uddin, S.J., Shaw, S., Islam, M.A., Ahmed, M.I., Chandra Shill, M., Karmakar, U.K., Yarla, N.S., Khan, I.N., Billah, M.M., Pieczynska, M.D., Zengin, G., Malainer, C., Nicoletti, F., Gulei, D., Berindan-Neagoe, I., Apostolov, A., Banach, M., Yeung, A.W.K., El-Demerdash, A., Xiao, J., Dey, P., Yele, S., Jóźwik, A., Strzałkowska, N., Marchewka, J., Rengasamy, K.R.R., Horbańczuk, J., Kamal, M.A., Mubarak, M.S., Mishra, S.K., Shilpi, J.A., Atanasov, A.G., 2018. Phytol: a review of biomedical activities. Food Chem. Toxicol. 121, 82-94.

Jung, M., Park, M., 2007. Acetylcholinesterase inhibition by flavonoids from Agrimonia pilosa. Molecules 12, 2130-2139.

Kativu, S., 1996. Asphodelaceae of the Flora Zambesiaca Area. Kirkia 16, 27-53.

Kellerman, T., Coetzer, J., Naudé, T., 2005. Plant Poisonings and Mycotoxicoses of Livestock in Southern Africa, Second Edi. Oxford University Press, Cape Town.

Klopper, R.R., Smith, G.F., van Wyk, A.E., 2013. Proposal to conserve the family name Asphodelaceae (Spermatophyta: magnoliidae: asparagales). Taxon 62, 402-403.

Lionetto, M.G., Caricato, R., Calisi, A., Giordano, M.E., Schettino, T., 2013. Acetylcholinesterase as a biomarker in environmental and occupational medicine: new insights and future perspectives. Biomed. Res. Int. 2013, 321213.

Maggi, F., Bílek, T., Lucarini, D., Papa, F., Sagratini, G., Vittori, S., 2009. Melittis melissophyllum L. subsp. melissophyllum (Lamiaceae) from central Italy: a new source of a mushroom-like flavour. Food Chem 113, 216-221.

Mannheimer, C., Marais, A., Schubert, A., 2012. Toxic plants of veterinary importance in Namibia, Ministry of Agriculture, Water and Forestry. 2nd Edi Windhoek.

Masondo, N.A. Stafford, G.I. Aremu, A.O. Makunga, N.P. 2019. Acetylcholinesterase inhibitors from southern African plants: an overview of ethnobotanical, pharmacological potential and phytochemical research including and beyond Alzheimer's disease treatment. South African J. Bot. 120, 39-64.

Massoulié, J., 2002. The origin of the molecular diversity and functional anchoring of cholinesterases. Neurosignals 11, 130-143.

Meshorer, E., Soreq, H., 2006. Virtues and woes of AChE alternative splicing in stressrelated neuropathologies. Trends Neurosci 29, 216-224.

Newsholme, S.J., Schneider, D.J., Reid, C., 1985. A suspected lipofuscin storage disease of sheep associated with ingestion of the plant, Trachyandra divaricata (Jacq.) Kunth. Onderstepoort J. Vet. Res. 52, 87-92.
Park, S.E., Kim, N.D., Yoo, Y.H., 2004. Acetylcholinesterase plays a pivotal role in apoptosome formation. Cancer Res 64, 2652-2655.

Paulus, J.M., Maigne, J., Keyhani, E., 1981. Mouse megakaryocytes secrete acetylcholinesterase. Blood 58, 1100-1106.

Pick, M., Flores-Flores, C., Grisaru, D., Shochat, S., Deutsch, V., Soreq, H., 2004. Bloodcell-specific acetylcholinesterase splice variations under changing stimuli. Int. J. Dev. Neurosci. 22, 523-531.

Pino, J.A., Mesa, J., Muñoz, Y., Martí, M.P., Marbot, R., 2005. Volatile components from mango (Mangifera indica L.) cultivars. J. Agric. Food Chem. 53, 2213-2223.

Radulovic, N., Blagojevic, P., Palic, R., 2010. Comparative study of the leaf volatiles of Arctostaphylos uva-ursi (L.) Spreng. and Vaccinium vitis-idaea L. (Ericaceae). Molecules 15, 6168-6185.

Rhee, J-.S., Kim, B.-.M., Jeong, C.-B., Park, H.G., Leung, K.M.Y., Lee, Y.-M., Lee, J--S., 2013. Effect of pharmaceuticals exposure on acetylcholinesterase (AchE) activity and on the expression of AchE gene in the monogonont rotifer, Brachionus koreanus. Comp. Biochem. Physiol. C. Toxicol. Pharmacol. 158, 216-224.

Sathya, S., Manogari, B.G., Thamaraiselvi, K., Vaidevi, S., Ruckmani, K., Devi, K.P., 2020. Phytol loaded PLGA nanoparticles ameliorate scopolamine-induced cognitive dysfunction by attenuating cholinesterase activity, oxidative stress and apoptosis in Wistar rat. Nutr. Neurosci. 1-17.

Sathya, S., Shanmuganathan, B., Saranya, S., Vaidevi, S., Ruckmani, K., Devi, P., K., 2018. Phytol-loaded PLGA nanoparticle as a modulator of Alzheimer's toxic A $\beta$ peptide aggregation and fibrillation associated with impaired neuronal cell function. Artif. Cells, Nanomedicine Biotechnol. 46, 1719-1730.

Schubert, S., 2002. Trachyandra laxa (Rolbos) A poisonous plant of Namibia. Spotlight Agric. 62.

Sousa, G.F.d., Aguilar, M.G.d., Takahashi, J.A., Alves, T.M.A., Kohlhoff, M., Vieira Filho, S.A., Silva, G.D.F., Duarte, L.P., 2017. Flavonol triglycosides of leaves from Maytenus robusta with acetylcholinesterase inhibition. Phytochem. Lett. 19, 34-38.

Stein, S.E., Babushok, V.I., Brown, R.L., Linstrom, P.J., 2007. Estimation of Kováts retention indices using group contributions. J. Chem. Inf. Model. 47, 975-980.

Van Wyk, B.-.E., Van Heerden, F., Oudtshoorn, B., 2002. Poisonous Plants of South Africa. Briza Publications, Pretoria, South Africa.

Voss, U., Sand, E., Olde, B., Ekblad, E., 2013. Enteric neuropathy can be induced by high fat diet in vivo and palmitic acid exposure in vitro. PLoS ONE 8, e81413.

Wink, M., van Wyk, B.-.E., 2008. Mind-altering \& Poisonous Plants of the World, 1st. ed Briza Publications, Pretoria

Xian, Q., Chen, H., Liu, H., Zou, H., Yin, D., 2006. Isolation and Identification of Antialgal Compounds from the Leaves of Vallisneria spiralis L. by Activity-Guided Fractionation. Environ. Sci. Pollut. Res. 13, 233-237.

Zajicek, J., 1957. Studies on the histogenesis of blood platelets and megakaryocytes; histochemical and gasometric investigations of acetylcholinesterase activity in the erythrocyte-erythropoietic and platelet-megakaryocytic systems of various mammals. Acta Physiol. Scand. Suppl. 40, 1-32. 